\title{
Quantitative determination of pore and throat parameters in tight oil reservoir using constant rate mercury intrusion technique
}

\author{
Hui Gao ${ }^{1} \cdot$ Tiantai $^{L^{1}} \cdot \operatorname{Ling}$ Yang $^{1}$
}

Received: 6 February 2015/ Accepted: 23 May 2015/Published online: 3 June 2015

(c) The Author(s) 2015. This article is published with open access at Springerlink.com

\begin{abstract}
The development of tight oil depends on the characteristics of complicated pore throat parameters. In this study, the tight oil samples obtained from the Yanchang group of Ordos basin (China) are tested using the constant rate mercury intrusion technique to quantitatively determine the size of pore and throat parameters, as well as analyze the key parameters that control the quality of tight oil reservoir. The pore radius of sample analogously distributes in $100-200 \mu \mathrm{m}$ and average pore radius varies from 103.7 to $139.74 \mu \mathrm{m}$. When the permeability is less than $1 \times 10^{-3} \mu \mathrm{m}^{2}$, the throat peak radius and the average throat radius will be less than $1 \mu \mathrm{m}$; furthermore, the variation of throat distribution is in the range of $0.2-0.5$ and $0.2-1.0 \mu \mathrm{m}$. On the contrary, if the permeability is greater than $1 \times 10^{-3} \mu \mathrm{m}^{2}$, the average throat radius will be greater than $1 \mu \mathrm{m}$ and the distribution range of throat will spread from $0.2-3.4$ to $0.2-8.8 \mu \mathrm{m}$. As for the eleven samples, the main flow throat radius lies in the range of $0.41-3.71 \mu \mathrm{m}$, the throat quantity changes wildly from 1324 to 4271 number $/ \mathrm{cm}^{3}$, the average pore throat ratio varies from 503.59 to 86.11 , the pore mercury saturation alters in $17.65-55.95 \%$ and the throat mercury saturation distributes in $13.44-27.6 \%$. It can be learned that there is no obvious difference in pore parameters for tight oil reservoir. Therefore, the difference of pore throat structure mainly existed in throat parameters, and the throat parameters are the key factors that affect the physical properties and recovery results.
\end{abstract}

Hui Gao

ghtopsun1@163.com

1 College of Petroleum Engineering, Xi' an Shiyou University, No.18 Dianzi 2nd Road, Xi' an 710065, Shaanxi, People's Republic of China
Keywords Pore throat size - Quantitative determination . Tight oil · Constant rate mercury intrusion · Ordos basin

\section{Introduction}

With the increasing demands on energy and exhausting conventional resources, unconventional tight oil reservoirs are becoming important, and how to effectively develop them becomes a focus (Akanji et al. 2013; Yang et al. 2013). Tight oil reservoirs normally have complicated pore throat parameters, which determine the reservoirs quality and affect the oilfield development. Therefore, it is very important to quantitatively determine the dominant pore and throat parameters. Mercury injection method is a widely used technique for the evaluation of capillary pressure, pore size and throat size since Purcell introduced the technique to the industry (Brooks and Corey 1981; Katz and Thompson 1981, 1987; Pittman 1992; Purcell 1949). Mercury intrusion is a very useful method to gain quantitative data on the pore throat parameters. The measurement of pore throat size distributions from mercury intrusion has been of great benefit to reservoir evaluation in the oil and gas industry. Other petrophysical characteristics such as porosity, relative permeability and irreducible water saturation can be determined using mercury porosimetry (Vavra et al. 1992). Matthew et al. (1993) used the mercury intrusion to calculate network and absolute permeability in sandstone and other porous media. Lambropoulos et al. (2007) applied an innovative mercury intrusion technique and relative permeability to examine the thin layer pores of sol-gel and CVD post-treated membranes. Yao and Liu (2012) characterized pore size distributions of coals with low-field NMR and mercury intrusion porosimetry. 
Sasanian and Newson (2013) used mercury intrusion porosimetry for microstructural investigation of reconstituted clays at high water contents. Okolo et al. (2015) compared the porosity and surface areas of different coals as measured with mercury intrusion. Capillary pressure curves normally give information only on throat sizes rather than on the exact volume of the pore space (Yuan and Swanson 1989). In the usual experiment, mercury pressure is raised in increments and the injected mercury volume is measured. This is a pressure-controlled measurement of mercury capillary pressure curve. On account of the inherent ambiguity in capillary pressure curves, attempts to derive relationships between various petrophysical properties through capillary pressures are not always successful. Due to the conventional (pressurecontrolled) method nature of measuring capillary pressure curves, it is possible to have different distributions of pore systems that would lead to the same capillary pressure curve. While the rate-controlled measurement can overcome the shortage of conventional mercury intrusion to get the quantity of pores and throats, draw capillary pressure curves of pores and throats, respectively, and obtain more accurate micro-pore structure characteristic parameters (Crawford and Hoover 1966; Morrow 1970; Yuan and Swanson 1989; Gao et al. 2013). The observation of fluctuations in mercury pressure during mercury injection is not new. In 1959, in an unpublished Shell report, Gates observed pressure fluctuations with mercury porosimetry measurement for vuggy carbonates. In 1966, Crawford and Hoover (1966) recorded capillary pressure fluctuations on a chart recorder during injecting the water into synthetic porous media. The infinitesimally slow displacement of a wetting fluid by a non-wetting fluid was discussed in detail by Morrow (1970). He introduced terminology to describe certain features of the pressure fluctuations that we describe in the latter section. In 1971, Gaulier (1971) published similar techniques for depicting vug volume, although the sensitivity was very low. From then on, some studies have been done to analyze the pore and throat parameters of low permeability sandstone ( $\mathrm{Yu}$ et al. 2006; Hao et al. 2007; Lin et al. 2008; Gao et al. 2013). Nevertheless, up to now, there are only few researches that have applied the constant rate mercury intrusion to tight oil rocks and examined their pore and throat parameters.

In this research, the constant rate mercury intrusion experiments are carried out in tight oil reservoir of Ordos basin to determine the pore and throat sizes. It is meaningful to reveal the key factors affecting physical property and the efficient oil recovery in tight oil reservoirs.

\section{Experiment setup and terminology}

The experiment equipment is one of the most advanced equipments used domestically or internationally, which is named ASPE-730 manufactured by American Core-test Systems (see Fig. 1). Different from conventional mercury intrusion, mercury is injected at a very low speed $(0.000001-1 \mathrm{cc} / \mathrm{min})$ in constant rate mercury intrusion to guarantee pseudo-static state. The injection pressure varies from 0 to $1000 \mathrm{psi}$ with the accuracy of $0.05 \%$. The sample is manufactured into the cylinder with the diameter and length of $1 \mathrm{~cm}$ or less than $1 \mathrm{~cm}$.

An alternative method of measuring capillary pressure curves is by rate-controlled injection of mercury into the sample, where the injection rate is kept constant and the mercury capillary pressure is monitored. Fluctuations in the mercury meniscus may occur due to various degrees of constriction along the pore throat. Because capillary pressure is inversely related to the curvature radius of the mercury meniscus, fluctuations in the curvature of the mercury meniscus respond as fluctuations in capillary pressure. The pore and throat radius can be calculated by the Eq. (1).

$P_{\mathrm{c}}=\frac{2 \times \sigma \times \cos \theta}{r}$

where $\sigma$ is the interfacial tension $(\mathrm{mN} / \mathrm{m}), r(\mu \mathrm{m})$ is the radius of the corresponding cylinder and $\theta$ is the contact angle $\left({ }^{\circ}\right)$. In the experiment, the interfacial tension of $\mathrm{Hg}$ is $485 \mathrm{mN} / \mathrm{m}$, the contact angle is $140^{\circ}$ and the maximum injection pressure is $900 \mathrm{psi}$, such that the corresponding minimum of pore throat radius is $0.12 \mu \mathrm{m}$.

The experiment setup and schematic plot is illustrated in the traditional way of wetting-phase volume increasing from the left to the right (see Fig. 1). While the volume of mercury injected increases from the right to the left. The important event that occurs, respectively, in an ASPE-730

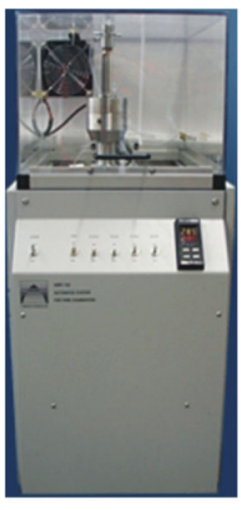

ASPE-730 Setup
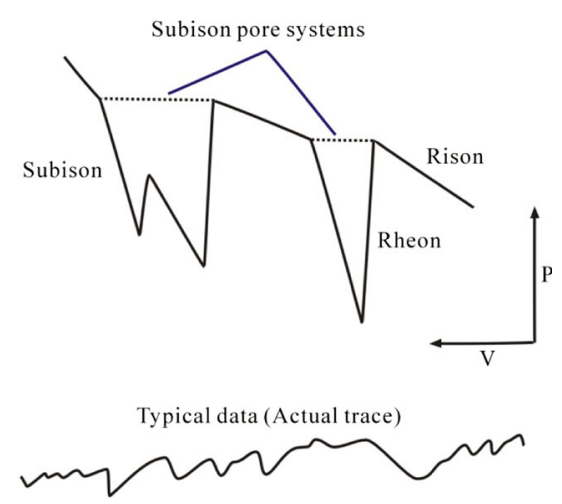

Schematic plot
Fig. 1 Experiment setup and schematic plot of ASPE-730 
experiment is the sudden drop in mercury pressure when a mercury meniscus passes from a throat into a wider pore body. By definition, Rheon reflects the sudden drop in capillary pressure, Rison shows the increasing capillary pressure to previously unattained levels, Subison means the increasing capillary pressure to previously attained levels, and Subison pore system is revealed by sequence of only Rheons and Subisons. Therefore, the pore throat information is gained according to the Rison and Subison, then the pore and throat size can be achieved (Yuan and Swanson 1989). The throat can be identified according to increasing capillary pressure (Rison), while the pore can be distinguished by the sudden drop in capillary pressure (Subison). Therefore, the throat quantity and pore quantity can be obtained, respectively. Based on the Eq. (1), the throat radius and pore radius can be calculated. The average throat radius $\left(R_{\mathrm{c}}\right)$, contribution of throat to permeability $\left(K_{i}\right)$, pore mercury saturation $\left(S_{\mathrm{p}}\right)$ and throat mercury saturation $\left(S_{\mathrm{t}}\right)$ can be calculated through the Eqs. (2)-(5) in order. The pore and throat size parameters gained from the experiment can reflect the dynamic characteristics of pores and throats in the process of fluid flow. So constant rate mercury intrusion is better fit for tight oil reservoir having bigger differences in pore and throat size.
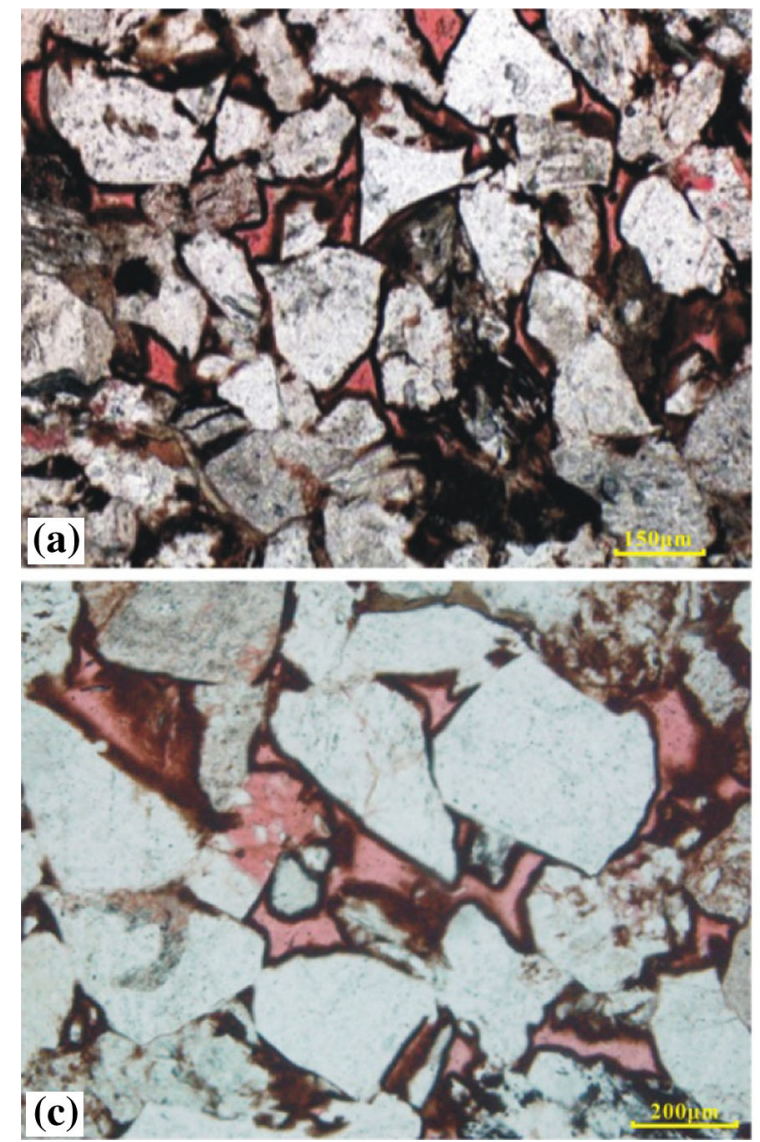

$R_{\mathrm{c}}=\sqrt{\left(\sum_{i=1}^{n} r_{i}^{2} \alpha_{i}\right)}$

$K_{i}=\frac{r_{i}^{2} \alpha_{i}}{\sum_{i=1}^{n} r_{i}^{2} \alpha_{i}}$

$S_{\mathrm{p}}=\frac{V_{\mathrm{p}}}{V} \times 100 \%$

$S_{\mathrm{t}}=\frac{V_{\mathrm{t}}}{V} \times 100 \%$

where $r_{i}$ is the throat radius $(\mu \mathrm{m}), a_{i}$ is the normalized frequency distribution of throat $(\%), V$ is the volume of core sample $(\mathrm{ml}), V_{\mathrm{p}}$ is the pore volume obtained from injection mercury $(\mathrm{ml}), V_{\mathrm{t}}$ is the throat volume obtained from injection mercury $(\mathrm{ml})$.

\section{Property of core samples}

As shown in Fig. 2 and Table 1, all eleven samples are obtained from Yanchang group in Ordos basin. The pore types are composed by intergranular pore and dissolution pore. The lithology is dominated by lithic feldspar
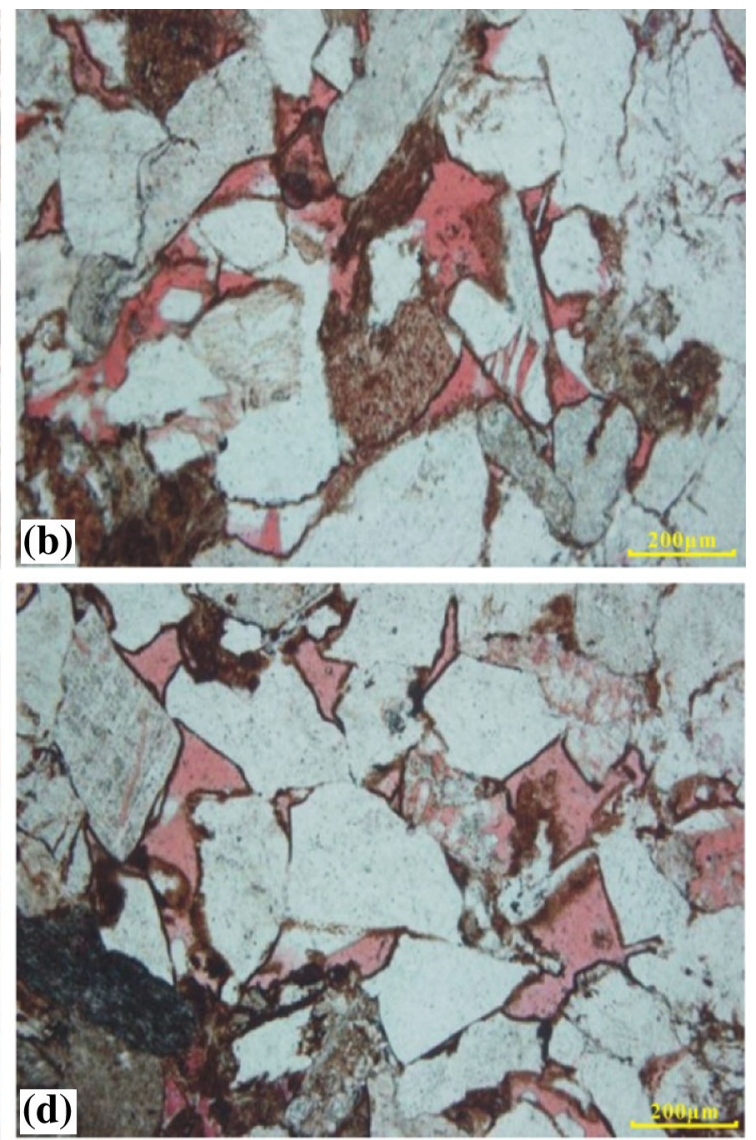

Fig. 2 Casting section of pore type of core sample Zh110 (a), X248 (b), Zh58 (c) and X259 (d)

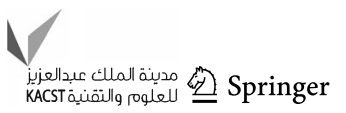


Table 1 Physical properties of core samples

\begin{tabular}{lllllll}
\hline Group & Sample number & Porosity $(\%)$ & Permeability $\left(10^{-3} \mu \mathrm{m}^{2}\right)$ & Lithology & Wettability & Sedimentary microfacies \\
\hline A & X250 & 11.00 & 0.10 & Lithic feldspar sandstone & Weak-oil wet & Braided river delta \\
& Zh110 & 9.90 & 0.16 & Feldspar lithic sandstone & Weak-oil wet & Braided river delta \\
& L22 & 11.63 & 0.17 & Feldspar lithic sandstone & Weak-water wet & Meandering river delta \\
& X256 & 10.40 & 0.23 & Lithic feldspar sandstone & Weak-oil wet & Braided river delta \\
X248 & 11.10 & 0.32 & Lithic feldspar sandstone & Weak-oil wet & Braided river delta \\
B & 16.70 & 1.37 & Lithic feldspar sandstone & Weak-oil wet & Braided river delta \\
& X25 & 11.00 & 1.72 & Lithic feldspar sandstone & Weak-oil wet & Braided river delta \\
Y44 & 13.58 & 2.19 & Feldspar lithic sandstone & Weak-water wet & Meandering river delta \\
& X259 & 13.90 & 2.20 & Lithic feldspar sandstone & Weak-oil wet & Braided river delta \\
& L132 & 12.58 & 3.01 & Feldspar lithic sandstone & Weak-water wet & Meandering river delta \\
X26 & 11.97 & 4.47 & Lithic feldspar sandstone & Weak-oil wet & Braided river delta \\
\hline
\end{tabular}

sandstone and feldspar lithic sandstone. The wettability is primarily weak-oil wet and weak-water wet. The braided river delta and meandering river delta are developed. Furthermore, the porosity of samples is distributed in the range of $9.90-16.70 \%$, and their permeability changes from $0.10 \times 10^{-3}$ to $4.47 \times 10^{-3} \mu \mathrm{m}^{2}$ (see Table 1). The samples are divided into two groups according to permeability. The first group (A) includes five samples with the permeability of $0.10-0.32 \times 10^{-3} \mu^{2}$, while six samples belong to the second group (B) with permeability varying from $1.37 \times 10^{-3}$ to $4.47 \times 10^{-3} \mu \mathrm{m}^{2}$.

\section{Results and discussion}

\section{Pore size distribution}

Figure 3 shows the pore distribution for the eleven samples. There exists no large difference in pore size, and the pore exhibits the normal distribution mainly in the $100-200 \mu \mathrm{m}$. It is noted that the relationship between the average pore radius and permeability is stronger than that between the average pore radius and porosity from Fig. 4 . However, the average pore radius does not exhibit a sharp increasing trend with the increasing permeability. The maximum of average pore radius is $139.74 \mu \mathrm{m}$, while the minimum value is $103.7 \mu \mathrm{m}$. Zhao et al. (2015) considered that the pore radius mostly lies within 50-250 $\mu \mathrm{m}$ and little variation amongst the eight samples from Chang 7 section for tight oil reservoir based on the rate-controlled porosimetry testing. So the result is in accord with this paper. AlKhidir et al. (2011) thought that the maximum pore radius of sample from the Permo-Carboniferous Shajara Formation is $173.9 \mu \mathrm{m}$ with an average pore size of $41.6 \mu \mathrm{m}$ using the high-pressure mercury injection.
Therefore, the eleven core samples in this paper are provided the larger pore radius.

\section{Throat size distribution}

It can be learned from Table 2 that the throat peak radius is less than $1 \mu \mathrm{m}$ and the maximum is $0.5 \mu \mathrm{m}$ when the permeability is less than $1 \times 10^{-3} \mu \mathrm{m}^{2}$. The distribution range of throat is narrow, changing from $0.2-0.5$ to $0.2-1.0 \mu \mathrm{m}$, and the throat peak radius slightly increases along with an increasing permeability (as illustrated in Fig. 3).

Nevertheless, as can be seen from Table 2 and Fig. 5, if permeability is greater than $1 \times 10^{-3} \mu \mathrm{m}^{2}$, the peak radius of throat will increase, distributing in $0.5-1.0 \mu \mathrm{m}$. At the same time, the distribution range of throat radius becomes wider obviously, changing from $0.2-3.4$ to $0.2-8.8 \mu \mathrm{m}$. In comparison, it is observed that the content of large throat is higher in group B than that in group A from Table 2. As for the eleven samples, the content of throat peak value radius decreases from maximum 72.3 to $6.62 \%$ with the increasing permeability. It can be found from Table 2 and Fig. 5 that there is a high content of smaller throats in tight oil reservoir. What is more, the lower the permeability is, the higher degree the smaller throat will develop. Compared to the throat radius of Mesaverde sandstone calculated by theoretical equation (Ziarani and Aguilera 2012) and the throat radius of Canadian tight oil reservoirs obtained from $\mathrm{N}_{2}$ adsorption (Ghanizadeh et al. 2015), the throat radius is larger in tight oil reservoir of Ordos basin.

It can be found that the contribution of throat to permeability distributes intensively in group A from the Fig. 6. As shown in Table 3, the contribution of less than $1 \mu \mathrm{m}$ throats can reach $100 \%$ for sample X250, sample Zh110, sample L22 and sample X256. The contribution of 

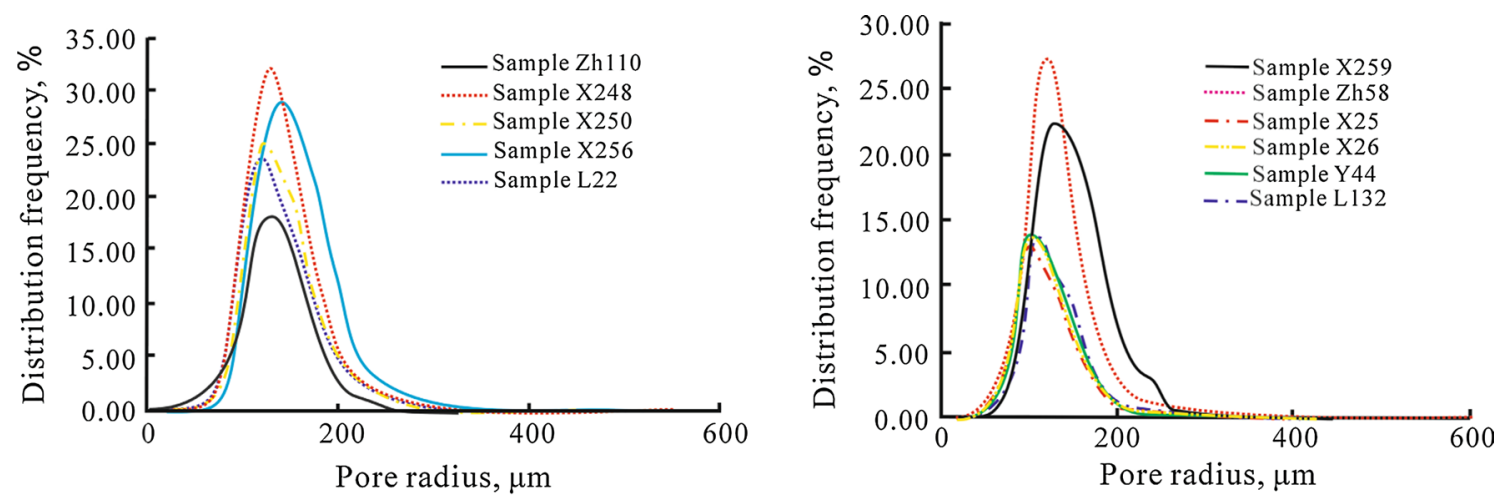

Fig. 3 Pore radius distribution of core samples
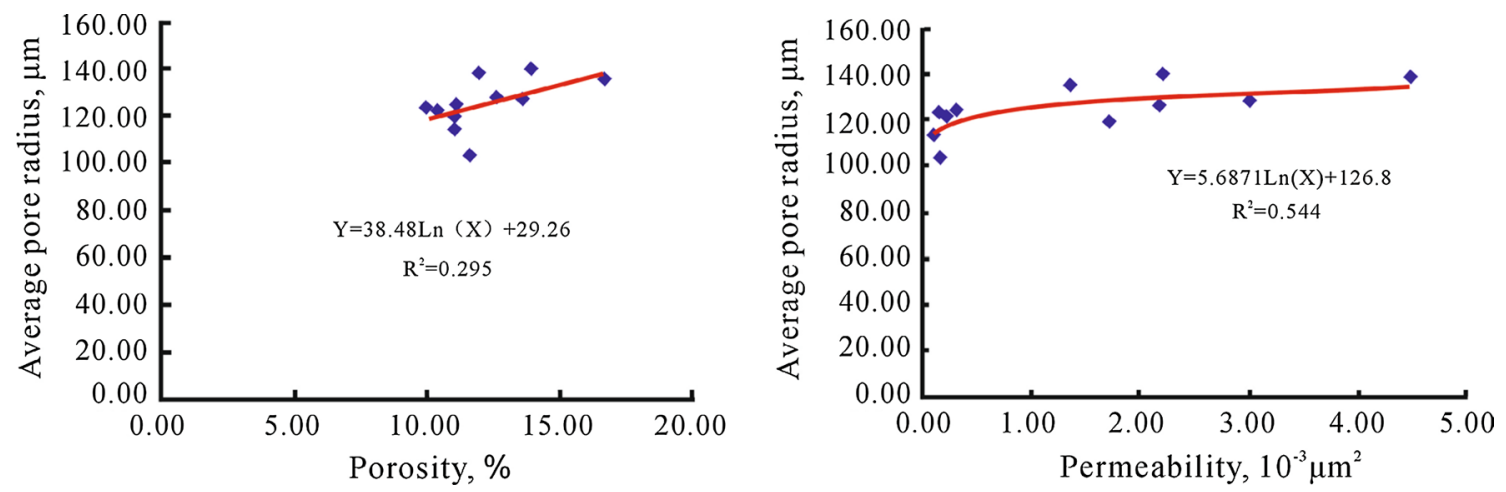

Fig. 4 Correlation between average pore radius and physical property

Table 2 Throat peak radius and distribution range of different core samples

\begin{tabular}{|c|c|c|c|c|}
\hline $\begin{array}{l}\text { Sample } \\
\text { number }\end{array}$ & $\begin{array}{l}\text { Permeability } \\
\left(10^{-3} \mu \mathrm{m}^{2}\right)\end{array}$ & Throat peak radius $(\mu \mathrm{m})$ & Distribution range of throat $(\mu \mathrm{m})$ & Content of throat peak value radius (\%) \\
\hline $\mathrm{X} 250$ & 0.10 & 0.4 & $0.2-0.5$ & 46.32 \\
\hline Zh110 & 0.16 & 0.4 & $0.2-0.9$ & 20.30 \\
\hline L22 & 0.17 & 0.4 & $0.2-0.8$ & 72.79 \\
\hline $\mathrm{X} 256$ & 0.23 & 0.5 & $0.2-0.9$ & 26.76 \\
\hline $\mathrm{X} 248$ & 0.32 & 0.5 & $0.2-1.0$ & 18.73 \\
\hline Zh58 & 1.37 & 0.5 & $0.2-3.4$ & 9.59 \\
\hline $\mathrm{X} 25$ & 1.72 & 0.8 & $0.2-8.0$ & 10.97 \\
\hline Y44 & 2.19 & 0.8 & $0.2-8.2$ & 12.79 \\
\hline $\mathrm{X} 259$ & 2.20 & 0.9 & $0.2-7.8$ & 6.62 \\
\hline L132 & 3.01 & 1.0 & $0.2-8.6$ & 6.83 \\
\hline $\mathrm{X} 26$ & 4.47 & 0.9 & $0.2-8.8$ & 7.39 \\
\hline
\end{tabular}

small throat to the permeability will be decreased with the increasing permeability.

As for the group B, contributions of throat to permeability are more dispersive because the contribution of bigger throat increases. Except for sample Zh58, the cumulative contributions of less than $4 \mu \mathrm{m}$ throat are less than $100 \%$ from Table 3 . It is indicated that the throat mainly contributing to permeability is not distributed in a certain range, but comes from a series of throats. It can be deduced that the recovery potential would be great because the flowing channel would be wide and flow resistance will be little for group B cores when there are larger throats.

It is learned that porosity has almost no correlation with average throat radius, as well as main flow throat radius 

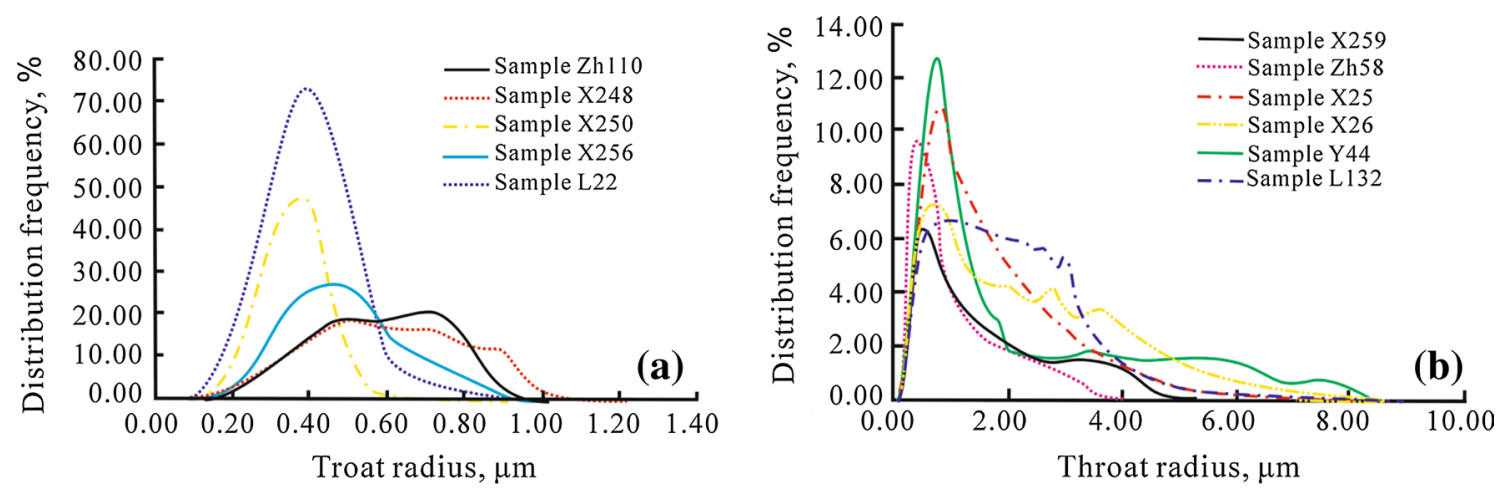

Fig. 5 Throat radius distribution of core samples
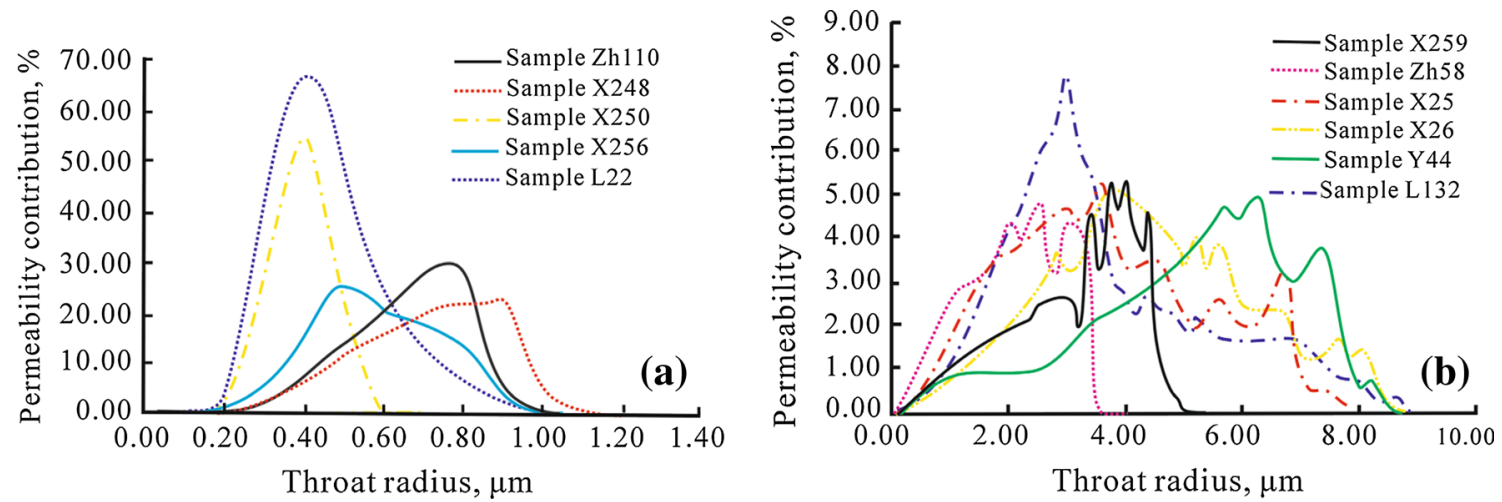

Fig. 6 Contribution of throat to permeability

Table 3 Comparison of cumulative contribution of throat to permeability among different core samples

\begin{tabular}{|c|c|c|c|c|c|c|}
\hline \multirow[t]{2}{*}{ Sample number } & \multirow[t]{2}{*}{ Permeability $\left(10^{-3} \mu \mathrm{m}^{2}\right)$} & \multicolumn{5}{|c|}{ Cumulative permeability contribution (\%) } \\
\hline & & $<1 \mu \mathrm{m}$ & $<2 \mu \mathrm{m}$ & $<3 \mu \mathrm{m}$ & $<4 \mu \mathrm{m}$ & $<5 \mu \mathrm{m}$ \\
\hline X250 & 0.10 & 100 & 100 & 100 & 100 & 100 \\
\hline Zh110 & 0.16 & 100 & 100 & 100 & 100 & 100 \\
\hline L22 & 0.17 & 100 & 100 & 100 & 100 & 100 \\
\hline X256 & 0.23 & 100 & 100 & 100 & 100 & 100 \\
\hline X248 & 0.32 & 95.11 & 100 & 100 & 100 & 100 \\
\hline Zh58 & 1.37 & 9.47 & 39.31 & 79.39 & 100 & 100 \\
\hline $\mathrm{X} 25$ & 1.72 & 2.04 & 15.18 & 35.34 & 58.25 & 74.49 \\
\hline Y44 & 2.19 & 2.05 & 15.59 & 40.27 & 59.68 & 74.11 \\
\hline X259 & 2.20 & 2.01 & 13.02 & 38.42 & 69.58 & 82.33 \\
\hline L132 & 3.01 & 1.11 & 11.56 & 37.62 & 64.31 & 76.42 \\
\hline X26 & 4.47 & 0.86 & 6.14 & 18.85 & 39.25 & 61.74 \\
\hline
\end{tabular}

and throat quantity from Figs. 7, 8 and 9. However, these three parameters all show a better correlation with permeability. The average throat radius is less than $1 \mu \mathrm{m}$ with a maximum value of $0.64 \mu \mathrm{m}$ when the permeability is less than $1 \times 10^{-3} \mu \mathrm{m}^{2}$ (see Table 4). However, if the sample permeability is greater than $1 \times 10^{-3} \mu \mathrm{m}^{2}$, the average throat radius will be greater than $1 \mu \mathrm{m}$ with a minimum value of $1.39 \mu \mathrm{m}$ (see Table 4 ).

The main flow throat radius of all samples distributes within $0.41-3.71 \mu \mathrm{m}$, and will become larger with the increasing permeability. Furthermore, it can be seen from Fig. 6 that the main flow throat radius varies significantly 

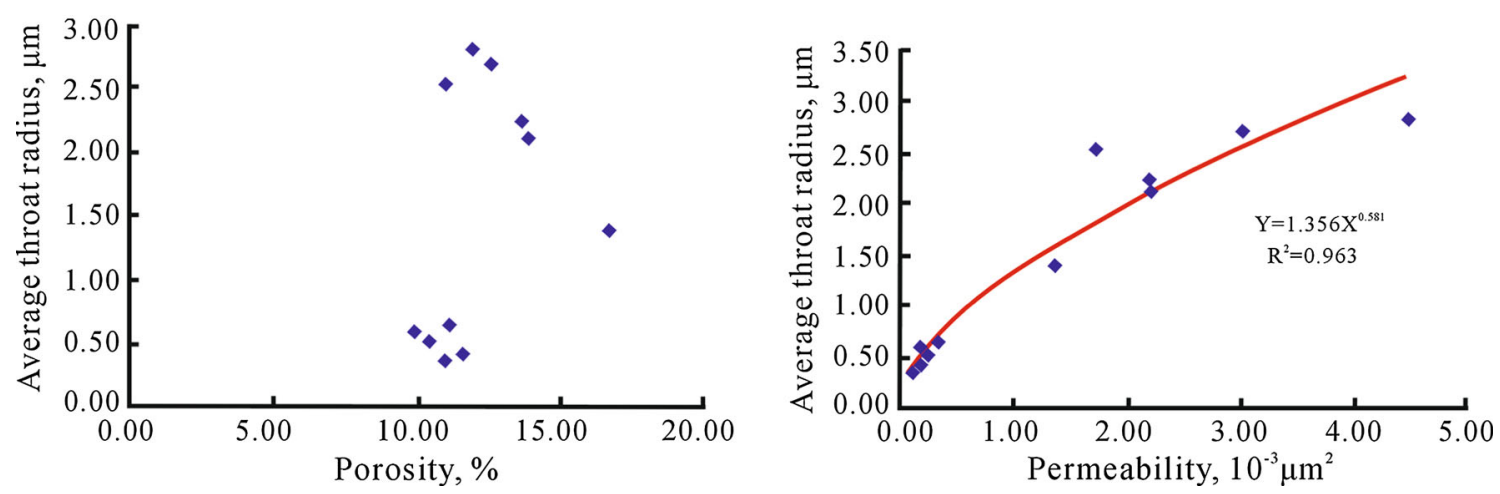

Fig. 7 Correlation between average throat radius and physical property
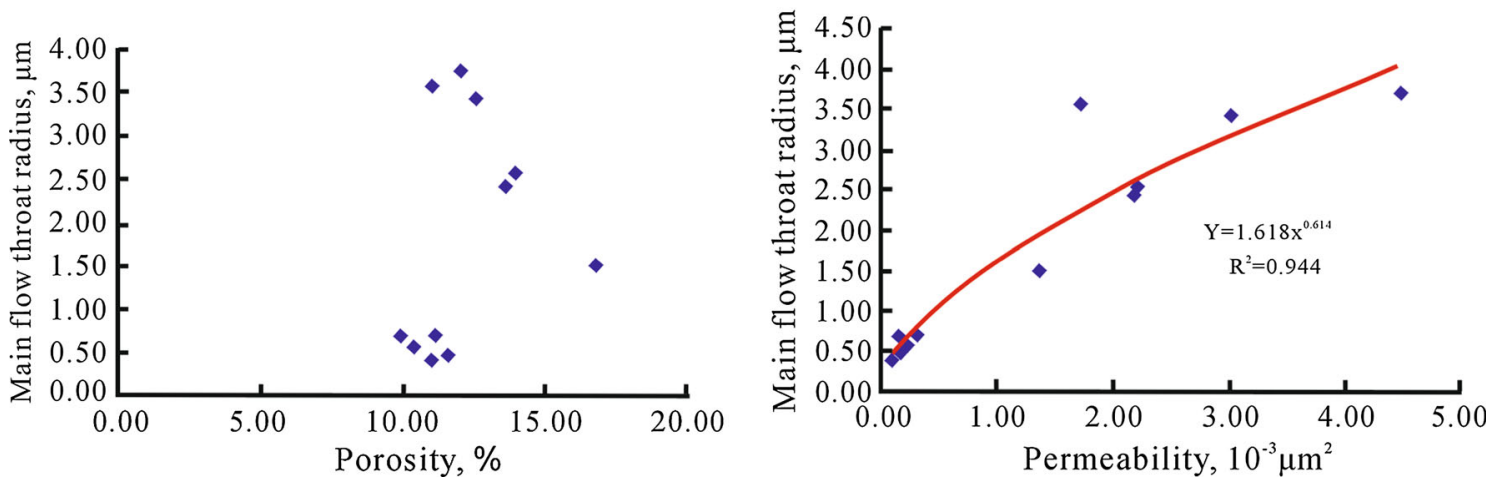

Fig. 8 Correlation between main flow throat radius and physical property

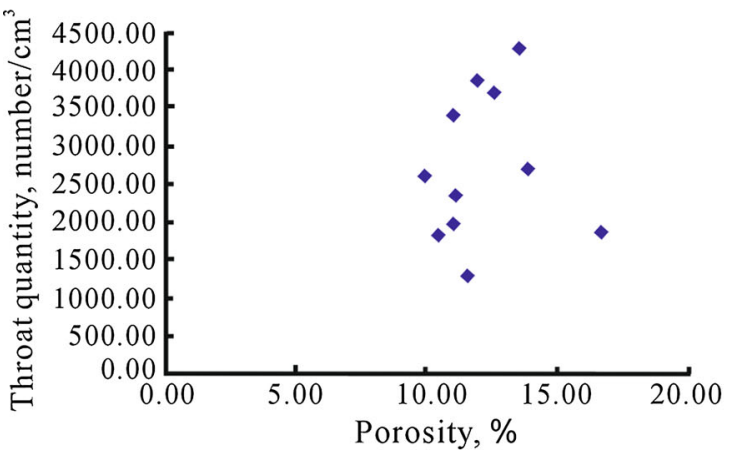

Fig. 9 Correlation between throat quantity and physical property

when the sample permeability is greater than $1 \times 10^{-3} \mu \mathrm{m}^{2}$. As shown in Table 4 and Fig. 9, the throat quantity of the sample changes wildly within the range of 1324-4271 number $/ \mathrm{cm}^{3}$.

As mentioned above, the permeability of tight oil reservoir is mainly contributed by poorly developed larger throats. However, the tight oil reservoir has a higher content of smaller throats. So it can be drawn that for tight oil reservoir, the difference of pore throat structure is presented in throat; the throat is the key factor that affects the

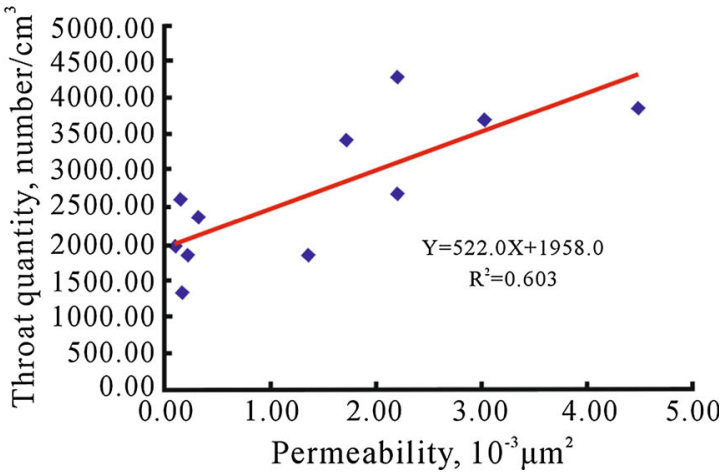

physical properties (especially permeability) and recovery results.

\section{Pore throat radius ratio}

Figure 10 shows that the pore throat ratio presents a declining trend with permeability, but has little correlation with porosity. The pore throat ratio of each sample exhibits a wide range of distribution over the range of $10-1000$. It is found that the content of bigger pore throat 
Table 4 Comparison of throat parameters among different core samples

\begin{tabular}{lllll}
\hline Sample number & Permeability $\left(10^{-3} \mu \mathrm{m}^{2}\right)$ & Average throat radius $(\mu \mathrm{m})$ & Main flow throat radius $(\mu \mathrm{m})$ & ${\text { Throat quantity }\left(\mathrm{number} \mathrm{cm}^{-3}\right)}^{\text {The }}$ \\
\hline X250 & 0.10 & 0.36 & 0.41 & 1973 \\
Zh110 & 0.16 & 0.6 & 0.69 & 2602 \\
L22 & 0.17 & 0.42 & 0.48 & 1324 \\
X256 & 0.23 & 0.52 & 0.57 & 2360 \\
X248 & 0.32 & 0.64 & 0.71 & 1851 \\
Zh58 & 1.37 & 1.39 & 1.51 & 3414 \\
X25 & 1.72 & 2.53 & 3.58 & 4271 \\
Y44 & 2.19 & 2.23 & 2.43 & 2695 \\
X259 & 2.20 & 2.11 & 2.56 & 3679 \\
L132 & 3.01 & 2.69 & 3.42 & 3863 \\
X26 & 4.47 & 2.81 & 3.71 & \\
\hline
\end{tabular}
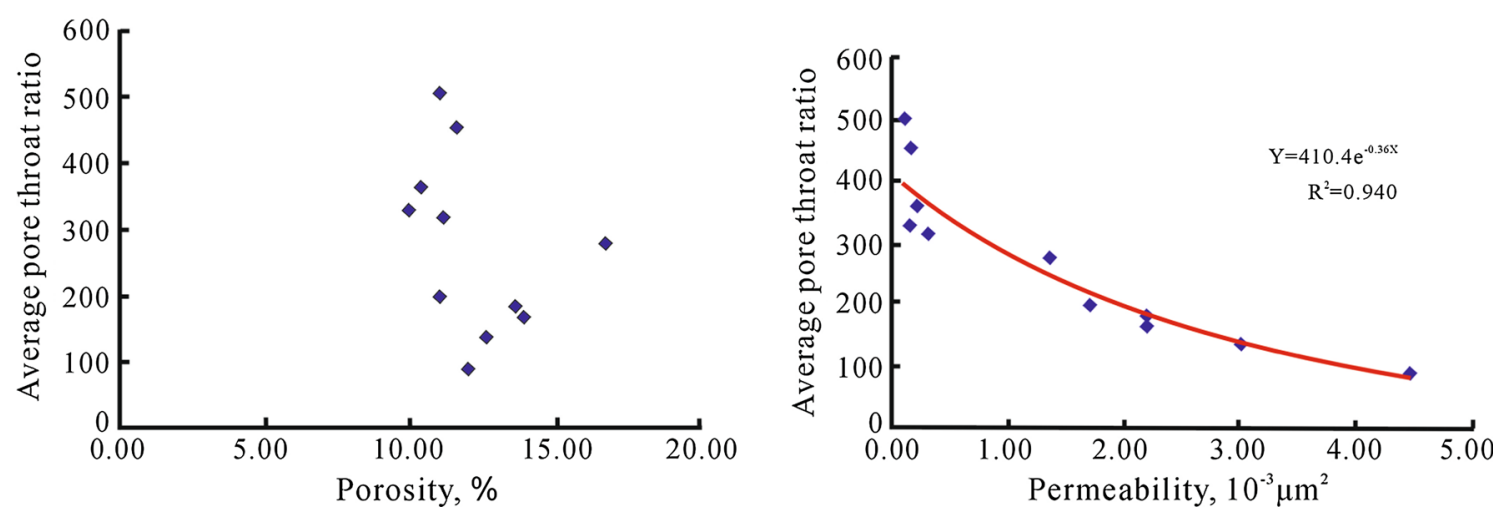

Fig. 10 Correlation between average pore throat ratio and physical property

ratio will decrease, and the average value of pore throat ratio varies from 503.59 to 86.11 with the increasing permeability (see Fig. 10). Pore throat ratio has a significant influence on displacement efficiency. A larger pore throat ratio means that the large pores are controlled by small throats. As a result, it is hard to recover oil from these pores and large amount of residual oil will exist. It can be seen that the low oil recovery in tight oil reservoir should be attributed to the larger pore throat ratio. So the distinguished feature of tight oil reservoirs from other

Table 5 Comparison of pore and throat mercury saturation among different core samples

\begin{tabular}{lllll}
\hline Sample number & Permeability $\left(10^{-3} \mu \mathrm{m}^{2}\right)$ & Pore mercury saturation $(\%)$ & Throat mercury saturation $(\%)$ & Total mercury saturation $(\%)$ \\
\hline X250 & 0.10 & 25.09 & 13.44 & 38.53 \\
Zh110 & 0.16 & 35.66 & 16.41 & 52.07 \\
L22 & 0.17 & 17.65 & 18.99 & 36.65 \\
X256 & 0.23 & 25.99 & 13.71 & 39.7 \\
X248 & 0.32 & 32.19 & 16.46 & 48.65 \\
Zh58 & 1.37 & 24.54 & 16.93 & 41.47 \\
X25 & 1.72 & 55.80 & 24.16 & 79.95 \\
Y44 & 2.19 & 51.69 & 20.84 & 72.52 \\
X259 & 2.20 & 27.66 & 20.07 & 47.73 \\
L132 & 3.01 & 49.10 & 22.39 & 71.49 \\
X26 & 4.47 & 59.55 & 27.60 & 87.15
\end{tabular}



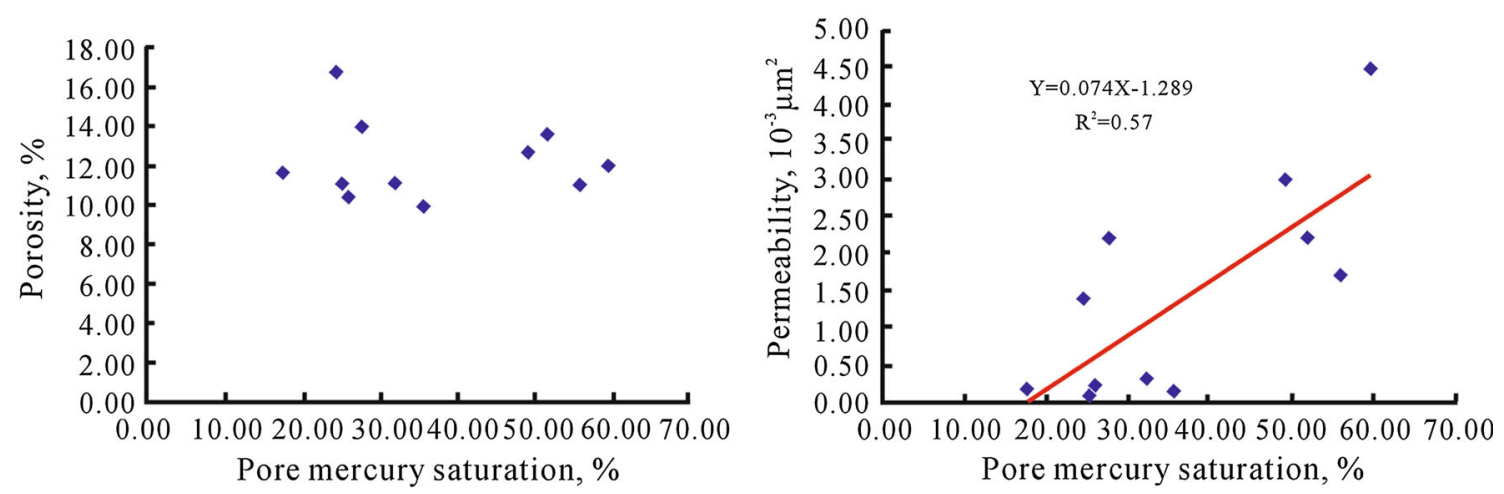

Fig. 11 Correlation between pore mercury saturation and physical property
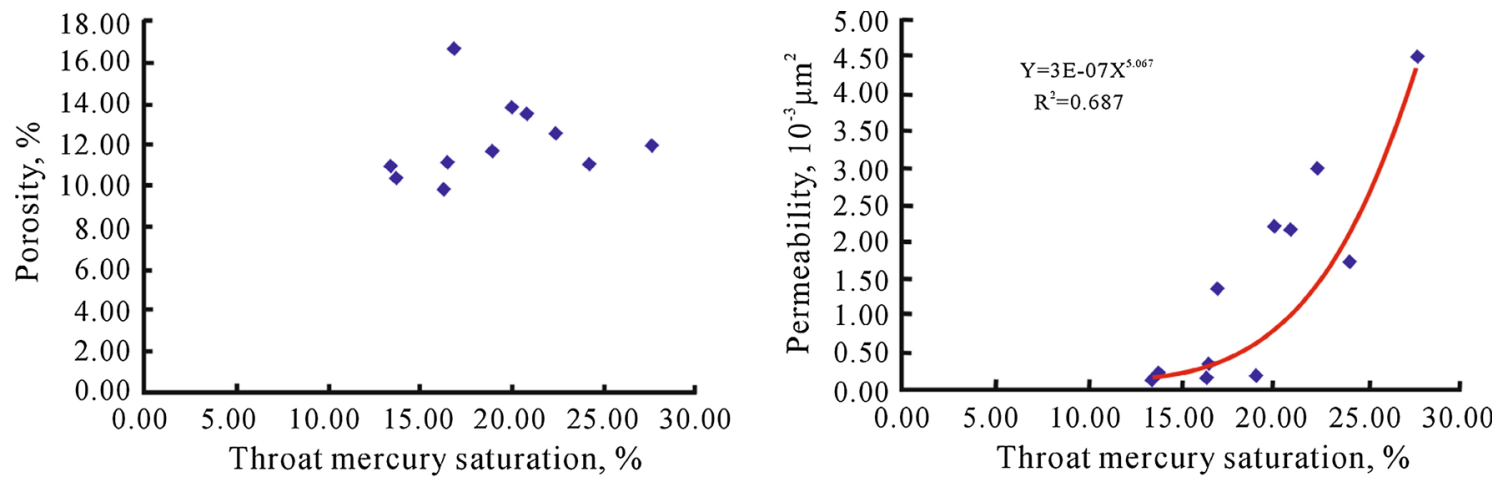

Fig. 12 Correlation between throat mercury saturation and physical property

conventional reservoirs is the large pore spaces and small throats (Zhao et al. 2015).

\section{Pore and throat volume}

Because the pore and throat can be distinguished using the constant rate mercury intrusion technique, the pore mercury saturation and throat mercury saturation can be determined, respectively. As shown in Table 5, the pore mercury saturation varies from 17.65 to $55.95 \%$, and the throat mercury saturation lies within the range of 13.44-27.60\%. As demonstrated in Figs. 11 and 12, the permeability exhibits a good correlation with pore mercury saturation, as well as throat mercury saturation. However, the porosity has almost no correlation with the pore mercury saturation and throat mercury saturation. By the definition of permeability, the permeability is macro-performance of throat parameters. Furthermore, the throat parameters determine pore connectivity and control the pore mercury saturation. According to the above analysis, the property of tight oil reservoir is primarily controlled by throat, instead of pore. As for the tight oil reservoir, it is very important to recover more oil from the pore spaces controlled by smaller throats. Therefore, the smaller throats should be primarily employed through decreasing the water injection velocity and using the spontaneous imbibitions of capillary. Then, the pores controlled by larger throats can be developed. In this way, the favorable oil recovery can be received.

\section{Conclusion}

In this study, pore and throat parameters in tight oil reservoir are quantitatively determined using constant mercury intrusion technique. The distribution ranges of pore in eleven tight core samples are almost the same, and the average pore radius does not exhibit a sharp change with the increasing permeability. If permeability is greater

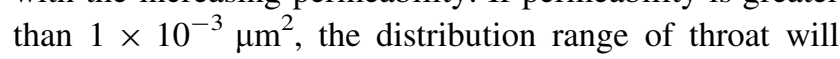
become more spreading out. It can be found that there is a high content of smaller throats in tight oil reservoir. Furthermore, larger throats will be present and a higher contribution of larger throat to permeability will be increased with the increasing permeability.

The average throat radius, main flow throat radius and throat quantity have almost no correlation with porosity, but show a good correlation with permeability. As for tight oil reservoir, the difference of pore throat structure is mainly presented in throat and the throat is the key factor 
that affects the physical properties (especially permeability) and oil recovery results.

The average pore throat ratio shows a declining trend with permeability, but has no correlation with porosity. The content of larger pore throat ratio will increase with the decreasing permeability. The low oil recovery in tight oil reservoir should be attributed to the larger pore throat ratio. The permeability exhibits a good correlation with pore mercury saturation, as well as throat mercury saturation. The higher the permeability is, higher amount the effective pore and throat will be.

Acknowledgments This research was financially supported by the National Natural Science Foundation of china (No. 41102081), Educational Ministry's Key Projects of China (No. 212172) and Natural Science Fundamental Research Grant of Shaanxi (No. 2012JQ5003).

Open Access This article is distributed under the terms of the Creative Commons Attribution 4.0 International License (http:// creativecommons.org/licenses/by/4.0/), which permits unrestricted use, distribution, and reproduction in any medium, provided you give appropriate credit to the original author(s) and the source, provide a link to the Creative Commons license, and indicate if changes were made.

\section{References}

Akanji LT, Nasr GG, Bageri M (2013) Core-scale characterisation of flow in tight Arabian formations. J Petrol Explor Prod Technol 3:233-241

Alkhidir KE, Alquraishi AA, Allaboun AA, Benzagouta MS (2011) Bimodal pore size behavior of the Shajara Formation Reservoirs of the Permo-Carboniferous Unayzah Group, Saudi Arabia. J Petrol Explor Prod Technol 1:1-9

Brooks RH, Corey AT (1981) A simple correlation between permeability and mercury capillary pressures. J Petrol Technol 3:2488-2504

Crawford FW, Hoover GM (1966) Flow of fluids through porous medium. J Geophys Res 71:2911-2917

Gao H, Jing XF, Zhang L (2013) Difference of micro-pore throat characteristics in extra-low permeability sandstone of different pore throat matching relationship. Petrol Geol Exper 35(4):401-406 (in Chinese)

Gaulier C (1971) Studying vugular rocks by constant-rate mercury injection. SPE 3612

Ghanizadeh A, Clarkson CR, Aquino S, Ardakani OH, Sanei H (2015) Petrophysical and geomechanical characteristics of Canadian tight oil and liquid-rich gas reservoirs: I. Pore network and permeability characterization. Fuel 153:664-681

Hao MQ, Liu XG, Hu YL (2007) Reservoir characteristics of microfractured ultra-low permeability reservoirs. Acta Petrol Sin 28(5):93-98 (in Chinese)
Katz AJ, Thompson AH (1981) Quantitative prediction of permeability in porous rock. Phys Rev B 34(11):8179-8181

Katz AJ, Thompson AH (1987) Prediction of rock electrical conductivity from mercury injection measurements. J Geophys Res 92(B1):599-607

Lambropoulos A, Romanos G, Steriotis T, Nolan J, Katsaros F, Kouvelos E, Charalambopoulou G, Kanellopoulos N (2007) Application of an innovative mercury intrusion technique and relative permeability to examine the thin layer pores of sol-gel and CVD post-treated membranes. Micropor Mesopor Mater 99:206-215

Lin YB, Zhang J, Liu XG (2008) Pore structure features of reservoirs at late high water-cut stage, Lamadian Oilfield, Daqing. Petrol Explor Dev 35(2):215-219 (in Chinese)

Matthew GP, Mossa AK, Spearingb MC, Voland F (1993) Network calculation of mercury intrusion and absolute permeability in sandstone and other porous media. Powder Tech 76:95-107

Morrow NR (1970) Physics and thermodynamics of capillary action in porous media. Ind Eng Chem Res 63:32-56

Okolo GN, Everson RC, Neomagus HW, Roberts MJ, Sakurovs R (2015) Comparing the porosity and surface areas of coal as measured by gas adsorption, mercury intrusion and SAXS techniques. Fuel 141:293-304

Pittman ED (1992) Relationship of porosity and permeability to various parameters derived from mercury injection capillary pressure curves for sandstone. AAPG Bull 76(2):191-198

Purcell WR (1949) Capillary pressures-their measurement using mercury and the calculation of permeability. Trans AIME 186:39-48

Sasanian S, Newson TA (2013) Use of mercury intrusion porosimetry for microstructural investigation of reconstituted clays at high water contents. Eng Geol 158:15-22

Vavra CL, Kaldi JG, Sneider RM (1992) Geological applications of capillary pressure: a review. Am Assoc Petrol Geol Bull 76:840-850

Yang P, Guo H, Yang D (2013) Determination of residual oil saturation during waterflooding in tight oil formations with NMR relaxometry measurements. Energy Fuel 27(10):5750-5756

Yao YB, Liu DM (2012) Comparison of low-field NMR and mercury intrusion porosimetry in characterizing pore size distributions of coals. Fuel 95:152-158

Yu JB, Guo DJ, Wang XQ (2006) Study of microscopic behaviors of low permeable reservoir through constant velocity mercury injection technique. J Daqing Petrol Inst 30(2):22-25 (in Chinese)

Yuan HH, Swanson BF (1989) Resolving pore space characteristics by rate-controlled porosimetry. SPE 14892

Zhao H, Ning Z, Wang Q, Zhang R, Zhao T, Niu T, Zeng Y (2015) Petrophysical characterization of tight oil reservoirs using pressure-controlled porosimetry combined with rate-controlled porosimetry. Fuel 154:233-242

Ziarani AS, Aguilera R (2012) Pore-throat radius and tortuosity estimation from formation resistivity data for tight-gas sandstone reservoirs. J Appl Geophys 83:65-73 